\title{
Sociologie
}

Sociologie 15(3): 241 - 251

(C) De auteur(s) 2019 (c) CC BY NC ND 4.0 † () (c) (1)

https://doi.org/10.5117/soc2019.3.001.oude

\section{Inleiding \\ De zichtbare hand: een historisch-sociologische benadering van neoliberalisme in Nederland}

\section{Merijn Oudenampsen \\ Universiteit van Amsterdam \\ m.oudenampsen@uva.nl}

\section{Bram Mellink}

Universiteit van Amsterdam

a.g.m.mellink@uva.nl

Keywords: neoliberalisme, ideeëngeschiedenis, beleid, kennissociologie, marktwerking

\section{Abstract}

O ince the financial crisis of 2008 , the international literature on neoliberalism is booming. Despite the ubiquity of neoliberalism as a topic in Dutch public debate, Dutch academia thus far seems to be an exception to the trend. This introduction reflects on the relative scarcity of Dutch academic literature on neoliberalism, provides a brief overview of recent developments in the international literature and proposes a historicalsociological approach to study neoliberalism, with particular emphasis on the pivotal role of ideas and their translation into policy practices. 


\section{Introductie}

Sinds de financiële crisis van 2008 heeft de term 'neoliberalisme' een snelle opmars gemaakt in het publieke debat. Bekende auteurs als Hans Achterhuis, Bram de Swaan en Maarten van Rossem brachten de crisis in verband met de opkomst van marktdenken in de jaren tachtig van de twintigste eeuw en de radicalisering van dat gedachtegoed sinds de val van de Berlijnse Muur (Achterhuis 2010; De Swaan 2010; Van Rossem 2011). Het idee dat de markt kon falen was daardoor steeds verder uit beeld geraakt, met de uiteindelijke implosie van Wall Street tot gevolg. Sindsdien laten (voormalig) politici als Lodewijk Asscher, Gert-Jan Segers, Hugo de Jonge, Jan Terlouw en Bert de Vries zich opvallend vaak uit over het neoliberalisme (Asscher 2019; Brandsma 2019; De Vries 2020; Oomkes en Zuidervaart 2018; Tjeenk Willink 2019; Tromp 2016). De strekking van hun betoog is dat het neoliberalisme is doorgeslagen, of met al te veel enthousiasme is doorgevoerd. Ook in bestuurlijke kring is er de laatste jaren een bijzondere belangstelling voor (de gevolgen van) neoliberaal beleid. Dat blijkt bijvoorbeeld uit het rapport Dertig jaar privatisering, verzelfstandiging en marktwerking van de WRR (Stellinga 2012) en het verslag van de Parlementaire Onderzoekscommissie Privatisering (2012; zie ook Kuiper 2014). Sommige journalisten constateren dan ook voorzichtig dat de hoogtijdagen van het 'geloof in de markt' achter ons lijken te liggen (Heijne 2019; Oomkes 2019).

Het is opvallend dat dit brede maatschappelijke debat tot nu toe weinig weerslag vindt aan de Nederlandse universiteiten. Internationaal, zoals we weldra zullen zien, is het neoliberalisme al tijden een toonaangevend onderzoeksonderwerp, in tal van sociaalwetenschappelijke disciplines. In Nederland echter, is er nog relatief weinig onderzoek naar verricht. Zeker, er zijn significante uitzonderingen (zie Hellema 2012; Scholten 1987; Van Apeldoorn 2009; Zuidhof 2012) maar het neoliberalisme als onderzoeksveld is nog opvallend onderontwikkeld in Nederland. Als gevolg daarvan kenmerkt het publieke debat over neoliberalisme zich veelal door wazige definities en grote onduidelijkheid over bepalende kenmerken, actoren en momenten. Zo is een belangrijk referentiepunt in de publieksboeken en beleidsrapporten de internationale omslag in het politieke en economische denken onder Reagan en Thatcher (Achterhuis 2010; Kuiper 2014; Van Rossem 2011; Tjeenk Willink 2019; Stellinga 2012). Deze opkomst van het marktdenken zou ook in Nederland zijn beslag hebben gekregen, maar hoe dat precies in zijn werk is gegaan, welke actoren daarin een doorslaggevende rol speelden, en hoe dat zich door de jaren heeft ontwikkeld blijft over het algemeen opvallend vaag. Was het de revanche van het bedrijfsleven? De overgang naar een postindustriële samenleving? Het failliet van de verzorgingsstaat? De dominantie van de financiële markten? De ultieme ideologische overwinning van het marktdenken? Het doorlopende proces van individualisering? Of toch een pragmatisch antwoord op de uitdagingen van de globalisering? Over de precieze aard van de omslag en over de drijvende krachten erachter is in Nederland nog maar weinig bekend. 
Deels heeft dit te maken met de achterstand in het empirisch onderzoek, deels wreekt zich ook een gebrek aan theoretische reflectie. De begripsverwarring is groot: is neoliberalisme een ideologie, een sociologisch proces, een tijdperk, een beleidspraktijk, een mindset of een samenlevingsvorm? Uit deze begripsverwarring hebben sommigen de conclusie getrokken dat het concept 'neoliberalisme' maar beter helemaal kan worden afgeschreven: de term zou onduidelijk en onwetenschappelijk zijn; wie onze huidige politiek-maatschappelijke problemen wil begrijpen, heeft niks aan dit soort vage leuzen (Oudenampsen en Mellink 2019; Van Hees et al. 2014). Het NWO-onderzoeksproject Market Makers probeert hierin verandering te brengen, door de ontwikkeling van het marktdenken in Nederland preciezer in kaart te brengen (Mellink 2017, 2020; Oudenampsen 2016, 2020). Als onderdeel van het onderzoeksproject werd in augustus 2019 aan de Universiteit Utrecht een interdisciplinair congres georganiseerd over de geschiedenis van het Nederlandse neoliberalisme, getiteld De zichtbare hand. Zoals de titel al aangeeft, gaat het congres uit van de vaststelling dat de vrije markt geen natuurlijke ordening is, als in de beroemde metafoor van de onzichtbare hand. Integendeel, marktwerking wordt juist actief vormgegeven door overheidsbeleid. Dit themanummer brengt enkele bijdragen aan dat congres bij elkaar. Voordat we echter dieper ingaan op de inhoud van de artikelen in dit themanummer, is het goed om eerst kort de balans op te maken van het internationale onderzoek naar neoliberalisme.

\section{Het internationale onderzoeksveld in vogelvlucht}

Het academische debat over neoliberalisme dat in Nederland grotendeels lijkt te ontbreken, is internationaal een toonaangevend gegeven. Het internationale onderzoek naar neoliberalisme heeft in de afgelopen decennia een razendsnelle ontwikkeling doorgemaakt, zoals alleen al blijkt uit de exponentiële toename van het aantal publicaties met de term 'neoliberalisme' in de titel. Vandaag de dag geldt het als een van de meest gebruikte sociaalwetenschappelijke concepten (Boas en Gans-Morse 2009; Peck 2010; Venugopal 2015) Onderzoek naar neoliberalisme vindt plaats binnen een brede reeks van disciplines, met enkele dominante theoretische benaderingen, waarvan elk weer eigen accenten legt. Een kort overzicht is op zijn plaats (voor uitgebreidere overzichten zie Davies 2014; Jessop 2013; Pinson en Journel 2016).

Een belangrijke onderzoeksrichting is de ideeëngeschiedenis, waar aan de hand van archiefonderzoek de ontwikkeling van het internationale intellectuele netwerk rond boegbeelden als Friedrich Hayek en Milton Friedman wordt getraceerd. In het laatste decennium is er een aantal toonaangevende studies verschenen over de geschiedenis van de neoliberale beweging, met als zwaartepunt de periode van de jaren dertig tot de jaren tachtig (Audier 2012; Burgin 2012; Cooper 2017; Mirowski en Plehwe 2009; Slobodian 2018; Stedman Jones 2014). Daarnaast is er de institutionele analyse, ontwikkeld door politicologen, sociologen en politiek- 
economen, een onderzoeksveld dat zich richt op de doorwerking van ideeën binnen instituties. Een belangrijk onderwerp in dit onderzoek is de omslag van een keynesiaans economisch beleid naar een neoliberaal aanbodbeleid in de jaren tachtig en negentig (Blyth 2002; Hall 1993; Hay 2006; Scharpf en Schmidt 2000). Vanuit een kennissociologische en/of historisch-sociologische benadering houden sociologen zich eveneens met dit vraagstuk bezig (Mudge 2018; Prasad 2006; Fourcade, Gourinchas en Babb, 2002; Fourcade 2009). Er is een invloedrijke marxistische benadering, waarin het neoliberalisme bovenal wordt geïnterpreteerd als een klassenproject dat zijn wortels heeft in de internationale mobilisatie van de economische elite tegen de macht van arbeid in de jaren zeventig. Politiek economen hebben de toon gezet binnen deze stroming en benadrukken de rol van economische belangen en de invloed van bedrijfsleven en financiële sector (Harvey 2007; Konings 2018; Overbeek en Van Apeldoorn 2012). Daarnaast hebben ook sociaal-geografen zich op het neoliberalisme toegelegd: Jamie Peck, Neil Brenner en Nick Theodore (2002), Neil Smith (2008) en Adam Tickell (Peck en Tickell 2008) benaderen het neoliberalisme vanuit een ruimtelijk perspectief en proberen 'neoliberalisering' procesmatig te ontleden. Tenslotte is er de foucauldiaanse benadering, die zich richt op het neoliberalisme als bestuurstechniek. Hierbij ligt de nadruk op de rol van de overheid in het reguleren van gedrag. De foucauldianen bestuderen hoe subjecten worden gevormd, en hoe individuen worden aangemoedigd zichzelf opnieuw uit te vinden als ondernemer. Deze benadering zien we terugkomen binnen de sociologie, criminologie en de bestuurskunde (Foucault 2008; Rose 1990; Dean 2009; Schinkel en Van Houdt 2010).

Opvallend is dat de toonaangevende onderzoekers op het terrein van neoliberalisme weliswaar tot verschillende scholen behoren, maar dat het onderzoek veelal interdisciplinair van karakter is. Historische en sociaalwetenschappelijke analyses overlappen voor een belangrijk deel, en dat geldt eveneens voor de sociologische, politicologische, sociaalgeografische, politiek-economische en meer politiek-filosofische benaderingen. Kortom, het onderzoek naar neoliberalisme is een bij uitstek interdisciplinair veld. Verwonderlijk is dit bij nader inzien niet. Marktgericht denken heeft zich in de afgelopen vier decennia genesteld in uiteenlopende instituties, een verschijnsel dat zich overigens geenszins tot westerse democratieën beperkt (Ther 2016; Hellema 2019). Deze ontwikkeling heeft een lange voorgeschiedenis en raakt aan de ontwikkeling van politieke denkbeelden, aan economische belangentegenstellingen, aan de wijze waarop de overheid denkbeelden en wetenschappelijke expertise naar beleid vertaalt en aan hoe bestuur inwerkt op de samenleving. Voor het traceren van neoliberale denkbeelden en hun weerslag en invloed is nauwe samenwerking tussen verschillende disciplines vrijwel onontbeerlijk. 


\section{Een historisch-sociologische blik op de rol van ideeën}

Ook in dit themanummer van Sociologie zijn vertegenwoordigers van veel verschillende disciplines betrokken. Een belangrijk referentiepunt is een inzicht uit de internationale literatuur dat inmiddels gemeengoed is geworden: het neoliberalisme behelst geen eenduidige inperking van de staat ten gunste van de markt, maar bepleit een specifiek samenspel tussen die twee. Grofweg kan het neoliberalisme worden omschreven als een politieke filosofie die de samenleving zo ver mogelijk aan de hand van het marktmechanisme wenst te ordenen. De overheid dient de bestaansvoorwaarden voor de vrije markt te scheppen en te garanderen. Concurrentie is richtsnoer én toetssteen voor overheidsinterventies. Bij het neoliberalisme hoort dus geen uitgeholde, maar juist een sterke staat die 'planning for competition' in het vooruitzicht stelt (Hayek 1944: 43) en aan '[markt]conform ingrijpen' doet (Röpke 1948: 46). Hieruit ontstaat de paradox van marktwerking: enerzijds wordt de markt voorgesteld als een 'natuurlijke staat', waarnaar de overheid zich moet voegen, anderzijds wordt de markt door overheidsingrijpen vervolmaakt, of in sommige gevallen - zoals de quasi-markten in delen van de publieke sector zelfs gecreëerd (Oudenampsen 2016: 123; Zuidhof 2012: 221).

In de praktijk krijgt marktwerking op zoveel verschillende manieren gestalte, dat het ondoenlijk is om in een themanummer tot een systematisch, laat staan tot een sluitend overzicht te komen. De zes artikelen van dit themanummer laten zich daarom hoofdzakelijk lezen als verkenningen van neoliberalisme in Nederland, maar die verkenningen beginnen vanuit een gemeenschappelijk vertrekpunt: het samenspel tussen overheid en markt, gericht op vestiging of consolidatie van een concurrentieregime. De benadering is overwegend ideeënhistorisch en (kennis) sociologisch met bijzondere aandacht voor de complexe relatie tussen politieke ideeën en beleid. Ideeënhistorisch omdat het neoliberalisme ten eerste als een concreet gedachtegoed wordt benaderd, als een ideologische stroming waarvan de ontstaansgeschiedenis en verspreidingstrajecten kunnen worden getraceerd. Kennissociologisch omdat het uitgangspunt is dat ideeën niet simpelweg een afgeleide of dekmantel zijn van dominante economische belangen, zoals in de marxistische of politiek-economische benadering. Noch worden ideeën in filosofisch-idealistische zin beschouwd als een autonome, drijvende kracht achter historische ontwikkelingen. De kennissociologie bewandelt een tussenweg. Aan de ene kant wordt de manier waarop groepen hun belangen interpreteren, bepaald door dominante ideeën (bijvoorbeeld over hoe de economie werkt). Er bestaat dus niet een 'objectief' belang dat geheel losstaat van ideeën. Aan de andere kant zijn die ideeën niet autonoom maar sociaal gesitueerd, en dienen zij als instrument voor groepen om zich te organiseren (Mannheim 1960; Fourcade 2009; Mudge 2018; zie ook Oudenampsen 2018: 17-21).

Een institutionele pendant van deze benadering vinden we terug in het BritsAmerikaanse onderzoek naar de omslag in de jaren tachtig, waar onderzoekers chocola probeerden te maken van de krachtige marktretoriek en de polariserende 
strijd met de vakbonden onder Reagan en Thatcher (Blyth 2002; Hay 2006; Prasad 2006). Op het Europese continent, waar niet het polariserende tweepartijenstelsel maar een meer op compromis gestoeld meerpartijenstelsel domineerde, was deze omslag minder expliciet (Mudge 2018; Prasad 2006). In Nederland werden onder Ruud Lubbers termen als 'Nieuwe Zakelijkheid' en de 'BV Nederland' die 'gerund' en 'gemanaged' moest worden gemeengoed. Omdat deze hervormingen echter op vrij gedepolitiseerde en technocratische wijze werden doorgevoerd, kwam het tempo en de aard van de veranderingen pas later in beeld (Hellema 2012; Oudenampsen 2020; Schmidt 2003; Scholten 1987; Van Apeldoorn 2009; Zuidhof 2012).

Door het accent te leggen op ideeën en de doorwerking daarvan in beleid wijkt het themanummer af van een aantal andere benaderingen binnen het onderzoek naar neoliberalisme. Het behandelt neoliberalisme niet als retorische dekmantel voor het herstel van hiërarchische klassenverhoudingen of de uitbreiding van de macht van het grootbedrijf, zoals David Harvey (2005) en Colin Crouch (2011) hebben gedaan. Dit betekent niet dat de auteurs dit herstel van klassenverhoudingen of de machtsgreep van het grootbedrijf per se betwisten. De crux is dat ideeën een actievere rol krijgen toebedeeld. Verklaard moet worden waarom het grootbedrijf er eerder van overtuigd was dat het keynesianisme in haar belang was en later juist het vrije marktdenken omarmde. Er heeft dus niet enkel een verandering plaatsgevonden in de naakte machtsverhouding tussen kapitaal en arbeid. De 'bril' waarmee zowel kapitaal als arbeid hun belangen zijn gaan zien, is eveneens veranderd. De ideeën van de neoliberalen zelf worden zo in het onderzoek betrokken, om de aantrekkingskracht van deze marktgerichte ideologie beter te kunnen doorgronden.

Evenmin wordt neoliberalisme in dit themanummer behandeld als een soort 'shock-doctrine' (Klein 2007). Plotselinge omslagen maken deel uit van de geschiedenis van de neoliberale beweging, maar een van de opvallende karakteristieken van haar geschiedenis is toch de decennialange, continue ideeënontwikkeling van de neoliberalen, die terug gaat tot de jaren twintig en dertig (Mirowski en Plehwe 2009; Walpen 2004). Mede dankzij die lange geschiedenis heeft het neoliberalisme zich bovendien ontwikkeld tot een gevarieerde beweging met veel interne meningsverschillen, zoals dit overigens ook met concurrerende ideologieën zoals de christendemocratie en het socialisme het geval is. Neoliberalisme laat zich dan ook niet zozeer begrijpen als een helder afgebakend pensée unique met een eenduidige essentie, zoals Pierre Bourdieu poneerde (Bourdieu 1998). Er is geen 'neoliberalisme met een hoofdletter N', dat de vorm aanneemt van een 'economische tsunami die [zich] over de gehele planeet' laat gelden (Ong 2007: 3). Er bestaat geen puur neoliberalisme, dat vanuit een centrale locatie over de wereld is uitgerold, enkel hybride vormen daarvan die een samenspel vormen met al bestaande lokale beleidstradities (Ban 2016; Peck 2010). 


\section{Overzicht artikelen}

Het themanummer begint met een artikel van historicus Jonne Harmsma, die laat zien dat neoliberale ideeën een langere voorgeschiedenis hebben dan vaak wordt verondersteld. Harmsma legt de beginselen bloot van het 'nieuwe marktdenken' onder Nederlandse economen in de naoorlogse jaren, met bijzondere aandacht voor het economisch denken van voormalig premier, minister en centralebankpresident Jelle Zijlstra. Al in de vroege jaren vijftig schoot zelfbenoemd neoliberaal denken wortel in Nederland, gericht tegen 'planning' en 'staatssocialisme', maar ook tegen het klassiek-liberalisme, dat de overheid een passieve rol in de economie toedichtte (laissez-faire). Harmsma laat zien hoe het denken van Zijlstra en zijn leermeester F. de Vries belangrijke gelijkenissen vertoonde met vroeg neoliberaal gedachtengoed, en laat hiermee indirect zien dat Nederland al in een vroeg stadium een eigen neoliberale traditie kende, die in de jaren van Lubbers dus niet (volledig) uit Groot-Brittannië of de Verenigde Staten hoefde te worden geïmporteerd.

Over de omslag van de jaren tachtig gaan de stukken van historicus Paul van Trigt, die de geschiedenis van de persoonsgebonden budgetten in de zorg tegen het licht houdt, en politicologe Margo Trappenburg, die de dwarsverbanden tussen linkse idealen, christelijk communitarisme en neoliberalisme onderzoekt. Uit beide stukken blijkt dat het samenspel tussen overheid en markt in de praktijk leidt tot een mengsel van neoliberale, christendemocratische en sociaaldemocratische ideeën. Opvallend is dat juist de christendemocraten van de rechterflank opvallend marktgerichte opvattingen koesterden, en zich ontpopten tot prominente pleitbezorgers van beleid met een aanwijsbaar neoliberale signatuur.

Het stuk van politiek econoom Peter-Wim Zuidhof richt zich op de rol van Nederlandse adviesraden in het verbreiden van het neoliberalisme. Hij stelt dat het marktvertoog van deze adviesraden een duidelijk constructivistisch karakter heeft: het gaat er niet zozeer om de markt in te dammen of vrij te laten, maar om deze vorm te geven en in te zetten als bestuursmiddel. Opmerkelijk, vanuit internationaal perspectief, is de sterk technocratische en gedepolitiseerde toon van de rapporten, wat mogelijk een verklaring biedt voor de relatieve onzichtbaarheid van de omslag in Nederland. Tot slot benadrukt Zuidhof het discursieve spel met het idee van 'de markt', waarbij allerlei vormen van pseudo-markten worden bevorderd.

De aanwezigheid van marktgerichte elementen in beleid wijst echter niet noodzakelijkerwijs op (doelbewust ontwikkeld) neoliberalisme, waarschuwen migratiejurist Thomas Spijkerboer en stadshistoricus Tim Verlaan. Verlaan wijst op de symbiotische samenwerking tussen grote bedrijven en de overheid in de jaren zestig, toen in Utrecht het megacomplex Hoog Catharijne verrees. Deze soepele samenwerking tussen staat en kapitaal tijdens de hoogtijdagen van de verzorgingsstaat roept interessante vragen op: is het latere marktgerichte beleid van de jaren tachtig een gevolg van een ideologische doorbraak, of geven hierin andere (wellicht moeilijk beheersbare) institutionele samenwerkingsverbanden 
of kapitaalstromen de doorslag? Spijkerboer laat in zijn bijdrage over de rol van de luchtvaartindustrie in internationale grensbewaking zien dat marktwerking en de bewaking van raciale grenzen uitstekend kunnen samengaan, zelfs zonder dat dit samenspel een (aantoonbaar) beleidsdoel is geweest. Via de invoering van de pre-boardingcheck, die luchtvaartmaatschappijen namens overheden uitvoeren in het land van vertrek, zijn marktpartijen een belangrijke partner geworden in de handhaving van grenzen. Omdat aan inwoners van niet-westerse landen aanmerkelijk strengere eisen worden gesteld dan aan inwoners van westerse landen via de verstrekking van visums, worden op de internationale vliegmarkt ongelijke criteria gehanteerd, die in de praktijk in hoge mate samenvallen met raciale scheidslijnen. Marktwerking en alledaags racisme versterken elkaar aldus, zonder dat hier aantoonbaar sprake is van beleid dat dit beoogt. Dat maakt het aantal slachtoffers van dit systeem, dat bijvoorbeeld omkomt op zee op weg naar Fort Europa, niet minder dramatisch.

Met behulp van deze zes casussen, aangevuld met boekrecensies en een interview met de vooraanstaande neoliberalisme-onderzoeker Dieter Plehwe, poogt dit themanummer enkel voorzetten te geven voor verder onderzoek. Conclusies over de nabije toekomst kunnen er helaas nog niet uit worden getrokken. Of de neergang van het neoliberalisme, die sommige journalisten vandaag de dag voorspellen, werkelijk zijn beslag zal krijgen, valt nog te bezien. Plehwe heeft hierover zijn twijfels. Voor beleidsmakers lijkt marktwerking in veel opzichten nog steeds de norm. Hoe het neoliberalisme zich ideologisch verder zal ontwikkelen valt (getuige haar geschiedenis) moeilijk te voorspellen. Zeker is wel dat een grondige kennis van haar oorsprong, ontwikkeling en verspreiding helpt bij een beter begrip van hedendaagse ontwikkelingen.

\section{Literatuur}

Achterhuis, H. (2010) De utopie van de vrije markt. Rotterdam: Lemniscaat.

Apeldoorn, B. van (2009) A national case-study of embedded neoliberalism and its limits: The Dutch political economy and the 'no' to the European Constitution. In: B. van Apeldoorn, J. Drahokoupil en L. Horn (red.) Contradictions and Limits of Neoliberal European Governance. Basingstoke: Palgrave Macmillan, 211-231.

Asscher, L. (2019) Opstaan in het Lloyd Hotel. Amsterdam: Podium.

Audier, S. (2012) Néo-libéralisme(s): Une archéologie intellectuelle (17194507). Bernard Grasset. Ban, C. (2016) Ruling ideas: How global neoliberalism goes local. Oxford: Oxford University Press. Blyth, M. (2002) Great transformations: Economic ideas and institutional change in the twentieth century. New York: Cambridge University Press.

Boas, T.C. en J. Gans-Morse (2009) Neoliberalism: From new liberal philosophy to anti-liberal slogan. Studies in Comparative International Development, 44(2): 137-161, DOI: 10.1007/ s12116-009-9040-5. 
Bourdieu, P. (1998) The essence of neoliberalism. Le Monde Diplomatique, 1 december, https://mondediplo.com/1998/12/08bourdieu.

Brandsma, J. (2019) Hugo de Jonge: Ik wil dat mensen weten dat de overheid er voor hen is. Trouw, 29 augustus, https://www.trouw.nl/gs-ba6e8d42.

Brenner, N. en N. Theodore (2002) Cities and the Geographies of "Actually Existing Neoliberalism”. Antipode, 34(3): 349-379, DOI: 10.1111/1467-8330.00246.

Burgin, A. (2012) The great persuasion: Reinventing free markets since the depression. Cambridge: Harvard University Press.

Crouch, C. (2011) The strange non-death of neo-liberalism. Oxford: Polity Press.

Dardot, P. en C. Laval (2014) The new way of the world: On neoliberal society. Londen: Verso.

Davies, W. (2014) Neoliberalism: A bibliographic review. Theory, Culture \& Society, 31(7-8): 309317, DOI: $10.1177 / 0263276414546383$.

Dean, M. (2009) Governmentality: Power and rule in modern society. London: Sage.

Foucault, M. (2008) The birth of biopolitics: Lectures at the Collège de France, 1978-1979 (A. I. Davidson en G. Burchell, vert.). New York: Palgrave Macmillan.

Fourcade, M. (2009) Economists and Societies: Discipline and Profession in the United States, Britain, and France, 1890s to 1990s. New Jersey: Princeton University Press.

Fourcade-Gourinchas, M. en Babb, S. (2002) The Rebirth of the Liberal Creed: Paths to Neoliberalism in Four Countries. American Journal of Sociology, 108(3), 533-579, doi:10.1086/367922.

Hall, P.A. (1993) Policy paradigms, Social learning, and the state: The case of economic policymaking in britain. Comparative Politics, 25(3): 275-296.

Harvey, D. (2005) A brief history of neoliberalism. New York: Oxford University Press.

Hay, C. (2006) The genealogy of neoliberalism. In: R. Roy, A. Denzau en T. Willett (red.) Neoliberalism: National and regional experiments with global ideas. New York: Routledge, 73-92.

Hayek, F. (1944) The Road to Serfdom. Londen: Routledge.

Hees, M. van, P. van Schie en M. van de Velde (2014) Neoliberalisme: Een politieke fictie. Amsterdam: Boom.

Heijne, S. (2019) Ook op het Binnenhof zijn ze het erover eens: Marktwerking is mislukt. Maar hoe moet het dan wél in de publieke sector? De Correspondent, 17 januari, https:// decorrespondent.n1/9081/ook-op-het-binnenhof-zijn-ze-het-erover-eens-marktwerkingis-mislukt-maar-hoe-moet-het-dan-wel-in-de-publieke-sector/1161076845258-8ecab303.

Hellema, D. (2012) Nederland en de jaren zeventig. Amsterdam: Boom.

IMF (2016) Neoliberalism: Oversold? Finance \& Development, juni 2016, https://www.imf.org/ external/pubs/ft/fandd/2016/06/ostry.htm.

Jessop, B. (2013) Putting neoliberalism in its time and place: A response to the debate. Social Anthropology, 21(1): 65-74, DOI: 10.1111/1469-8676.12003.

Klein, N. (2007) The shock doctrine: The rise of disaster capitalism. New York: Picador.

Konings, M. (2018) Capital and time: For a new critique of neoliberal reason. Stanford: Stanford University Press.

Kuiper, R. (2014) De terugkeer van het algemeen belang: Privatiseringsverdriet en de toekomst van Nederland. Amsterdam: Van Gennep. 
Mannheim, K. (1960) Ideology and utopia: An introduction to the sociology of knowledge. Londen: Routledge \& Kegan Paul.

Mellink, B. (2017) Politici zonder partij: Sociale zekerheid en de geboorte van het neoliberalisme in Nederland (1945-1958). BMGN - Low Countries Historical Review, 132(4): 25-52.

Mellink, B. (2020) Towards the centre: Early neoliberals in the Netherlands and the rise of the welfare state, 1945-1958. Contemporary European History, 29(1): 30-43, DOI: 10.1017/ S0960777318000887.

Mirowski, P. en D. Plehwe (2009) The road from Mont Pèlerin: The making of the neoliberal thought collective. New Haven: Harvard University Press.

Mudge, S.L. (2018) Leftism reinvented: Western parties from socialism to neoliberalism. Cambridge: Harvard University Press.

Ong, A. (2007) Neoliberalism as a mobile technology. Transactions of the Institute of British Geographers, 32(1): 3-8, DOI: 10.1111/j.1475-5661.2007.00234.x.

Oomkes, L. (2019) Zijn de hoogtijdagen van het neoliberalisme voorbij? Trouw, 15 september, https://www.trouw.nl/gs-b1f7b4a5.

Oomkes, L. en Zuidervaart, B. (2018) ChristenUnie bindt de strijd aan met het neoliberalisme. Trouw, 2 juni.

Oudenampsen, M. (2016) A dialectic of freedom: The Dutch post-war clash between socialism and neoliberalism. Socialism and Democracy, 30(1): 128-148, DOI: 10.1080/08854300.2015.1132648.

Oudenampsen, M. (2018) The conservative embrace of progressive values: On the intellectual origins of the swing to the right in Dutch politics. Proefschrift, Tilburg University.

Oudenampsen, M. (2020) Between consensus and conflict: The Dutch depoliticized paradigm shift of the 1980s. Comparative European Politics, https://doi.org/10.1057/s41295-02000208-3.

Overbeek, H. en B. van Apeldoorn (2012) Neoliberalism in crisis. Basingstoke: Palgrave Macmillan.

Parlementaire Onderzoekscommissie Privatisering (2012) Verbinding verbroken: Onderzoek naar de parlementaire besluitvorming over de privatisering en verzelfstandiging van overheidsdiensten. Den Haag: Eerste Kamer.

Peck, J. (2010) Constructions of neoliberal reason. Oxford: Oxford University Press.

Peck, J. en A. Tickell (2002) Neoliberalizing space. Antipode, 34(3): 380-404, DOI: 10.1111/14678330.00247.

Pinson, G. en C.M. Journel (2016) The Neoliberal City: Theory, Evidence, Debates. Territory, Politics, Governance, 4(2): 137-153, DOI: 10.1080/21622671.2016.1166982.

Prasad, M. (2006) The politics of free markets: The rise of neoliberal economic policies in Britain, France, Germany, and the United States. Chicago: University of Chicago Press.

Röpke, W. (1948) Civitas humana: A humane order of society (C. Fox, vert.). Londen: W. Hodge. Rose, N. (1990) Governing the soul: The shaping of the private self. Londen: Routledge.

Rossem, M. van (2011) Kapitalisme zonder remmen: Opkomst en ondergang van het marktfundamentalisme. Amsterdam: Nieuw Amsterdam.

Scharpf, F.W. en V.A. Schmidt (2000) Welfare and Work in the Open Economy: Volume I: From Vulnerability to Competitivesness in Comparative Perspective Oxford: Oxford University Press. 
Schinkel, W. en F. van Houdt (2010) The double helix of cultural assimilationism and neo liberalism: Citizenship in contemporary governmentality. British Journal of Sociology, 61(4): 696-715, DOI: 10.1111/j.1468-4446.2010.01337.x.

Schmidt, V.A. (2003) How, where and when does discourse matter in small states' welfare state adjustment? New Political Economy, 8(1): 127-146, DOI: 10.1080/1356346032000078750.

Scholten, I. (1987) Corporatism and the neo-liberal backlash in the Netherlands. In: Political stability and neo-corporatism: Corporatist integration and societal cleavages in Western Europe. Londen: Sage, 120-152.

Slobodian, Q. (2018) Globalists: The end of empire and the birth of neoliberalism. Cambridge: Harvard University Press.

Smith, N. (2008) Neoliberalism is Dead, Dominant, Defeatable - Then What? Human Geography, $1(2): 1-3$.

Stedman Jones, D. (2014) Masters of the universe: Hayek, Friedman, and the birth of neoliberal politics. Princeton: Princeton University Press.

Stellinga, B. (2012) Dertig jaar privatisering, verzelfstandiging en marktwerking. Amsterdam: Amsterdam University Press.

Swaan, B. de (2010) Het financieel regime. Over de gevolgen van een moderne dwaalleer. Thomas More Lezing, 17 november.

Ther, P. (2016) Europe since 1989: A history. New Jersey: Princeton University Press.

Tjeenk Willink, H. (2019) Groter denken, kleiner doen. Amsterdam: Prometheus.

Tromp, B. (2016) Het kapitaal is nu helemaal de baas. De Volkskrant, 20 februari.

Venugopal, R. (2015) Neoliberalism as concept. Economy and Society, 44(2): 165-187, DOI: 10.1080/03085147.2015.1013356.

Vries, B. de (2020) Ontspoord kapitalisme. Amsterdam: Prometheus.

Walpen, B. (2004) Der Plan, das Planen zu beenden. Proefschrift, Universiteit van Amsterdam. Zuidhof, P.W. (2012) Imagining markets: The discursive politics of neoliberalism. Proefschrift, Erasmus Universiteit Rotterdam.

\section{Merijn Oudenampsen}

Merijn Oudenampsen is socioloog en is als postdoctoraal onderzoeker verbonden aan de Universiteit van Amsterdam. Hij onderzoekt de neoliberale beleidsomslag in de Nederlandse politiek in de jaren tachtig. Zijn onderzoek maakt deel uit van het NWO-project Market Makers, over de geschiedenis van neoliberalisme in Nederland. Eerder promoveerde hij op het proefschrift The conservative embrace of progressive values, over de intellectuele inspiratiebronnen van de Fortuyn-revolte.

\section{Bram Mellink}

Bram Mellink is historicus en universitair docent Nederlandse Geschiedenis aan de Universiteit van Amsterdam. Hij onderzoekt het vroege neoliberalisme in Nederland (1945-1975) met bijzondere aandacht voor de vertaling van ideeën naar beleid. Zijn onderzoek maakt deel uit van het NWO-project Market Makers, over de geschiedenis van neoliberalisme in Nederland. 